\title{
DIPLOMACIA Y NACIONALIDAD DEPORTIVA EN LOS MEDIOS DE COMUNICACIÓN ${ }^{1}$
}

\author{
Arnaud Richard \\ Academia Olímpica Nacional de Francia \\ arnaudrichard@academie.olympique.fr \\ Fecha de recepción: mayo 2019 \\ Fecha de aceptación: octubre 2019
}

DOI: http://doi.org/10.15366/citius2019.12.2.005

\section{Resumen:}

Los deportes se juegan de acuerdo con las reglas. Condicionar el respeto a las normas es una obligación. Su violación a menudo conduce a sanciones impuestas por organismos reconocidos o críticas por parte de algunos guardianes de la ética. No creemos que estemos en condiciones de juzgar, y mucho menos penalizar a nadie a través de nuestras obras. Sin embargo, queremos presentar herramientas científicas y proporcionar análisis que hagan posible decir, sobre la base de criterios académicos específicos, que una declaración dada no es respetuosa con una persona o demostrar que una forma (dada) promueve la difusión de una ideología (contrariamente al ideal olímpico). Esta contribución es una síntesis de la tesis doctoral en Ciencias del Lenguaje (defendida en 2009) y la continuación de la investigación universitaria combinada con una participación en el ámbito universitario y deportivo olímpico académico.

Palabras clave: Diplomacia, Deporte, nacionalidad deportiva, Deporte y medios.

\section{Title: SPORTS DIPLOMACY AND NATIONALITY IN THE MEDIA}

\begin{abstract}
:
Sports are played according to rules. Conditioning to the respect of rules is an obligation, failing which their violation often leads to sanctions imposed by recognized bodies or criticism by some guardians of ethics. We do not think we are in a position to judge, let alone penalize, anyone through our works. However, we wish to present scientific tools and provide analyses which make it possible to say, based on specific academic criteria, that a given statement is not respectful towards a person or to demonstrate that a (given) form promotes the spreading of a negative ideology (contrary to the Olympic ideal). This contribution is a synthesis of Ph.D. thesis in Language Sciences (defended in 2009) and the continuation of university research combined with an involvement in the university and academic Olympic sport milieu.
\end{abstract}

Key words: Diplomacy, Sport, sports nationality, Sport and media.

\section{Introducción}

El marco de los Juegos Olímpicos ofrece un espacio único para el establecimiento de relaciones internacionales y la diplomacia. En primer lugar, hemos establecido el marco de nuestras observaciones en relación con la diplomacia en el deporte y en el Olimpismo. Posteriormente, hemos propuesto adaptaciones metodológicas basadas en el análisis del discurso, con el objetivo de presentar

${ }^{1}$ El presente trabajo es la versión en español de la conferencia que fue presentada en francés por el autor en la 15th Session for Presidents or Directors of National Olympic Academies organizada por la Academia Olímpica Internacional, en su sede de Olimpia en mayo del 2019. 
consideraciones sobre la cobertura que los medios de comunicación brindan al deporte. Finalmente, se ha examinado la forma de presentar la nacionalidad y el deporte en sí mismo por parte de los medios de comunicación, con el fin de ofrecer ejemplos sobre cómo se entrelazan las diferentes dinámicas identitarias, desde la individualidad hasta la colectividad.

\section{Diplomacia en deporte y Olimpismo}

Comenzamos proponiendo una definición de la noción de diplomacia a través de varios ejemplos. Posteriormente observamos el caso particular de la diplomacia en el deporte, finalizando esta sección con la diplomacia en el Olimpismo.

\subsection{Diplomacia}

Existen multitud de definiciones de diplomacia. Con el objetivo de facilitar la comprensión de la perspectiva que se adoptará a lo largo de este trabajo, tomaremos como base teórica los trabajos de Constanze Villar (2008). De acuerdo con lo propuesto por el autor, el discurso diplomático puede ser resumido en dos formulaciones: «los instrumentos de las políticas internacionales» o «los instrumentos utilizados entre estados». Podemos ver claramente la dimensión instrumental preponderante que subyace a la necesaria operatividad expresada a nivel supra-nacional.

La dimensión pragmática es la dominante. Sin embargo, dos perspectivas pueden distinguirse de forma clara: la diplomacia bilateral y la diplomacia multilateral. Convencionalmente, la diplomacia bilateral tiene formas de operar positivas o negativas. Por otra parte, la diplomacia multilateral se encuentra caracterizada por sus dimensiones constructiva (prevención) o reactiva (de reacción ante una situación de crisis).

Para comprender mejor estos principios en detalle, nos permitimos analizar lo que sostienen en lo referente a su aplicación al mundo del deporte.

\subsection{Diplomacia en el deporte}

Tomamos por tanto la diplomacia en el deporte (o la diplomacia deportiva, de acuerdo con algunos autores) como la implementación en el mundo del deporte de alguna forma de diplomacia. Esto puede ser comprendido como aquellos instrumentos de comunicación utilizados entre estados en el campo del deporte.

La perspectiva bilateral podría hacer emerger modalidades de operatividad positivas (Villar, 2008) a través de la apertura de relaciones, delegación de asesores especiales, visitas de personalidades de Estado, negociaciones, intervención de los mediadores o la apertura de canales diplomáticos oficiales.

Aplicadas al mundo del deporte, estos compromisos suponen una puesta en acción de gran calibre. Las Federaciones Nacionales o los Comités Olímpicos Nacionales en ocasiones debaten formalmente dentro del marco oficial. Los cabezas del Estado pueden asistir a una competición deportiva, a la vez que el deporte en sí mismo puede ser el vehículo o la ocasión elegida para mantener una reunión entre dos países. Podríamos mencionar algunos de los ejemplos más destacados, como la «diplomacia ping-pong», como se conoce popularmente al encuentro entre Estados Unidos y la República Popular de China (con el Presidente Nixon en el año 1971). 
Por el contrario, como ejemplos de formas de operar negativas podríamos encontrar el retiro de embajadores, la suspensión de relaciones, el corte directo de relaciones, las protestas, la ruptura de negociaciones o la expulsión de ciudadanos extranjeros.

En el ámbito del deporte, los equipos pueden verse concebidos como símbolos estatales y, por lo tanto, también estar sujetos a la voluntad de su jefe de estado. La negativa a luchar y la descalificación contra un oponente no es desconocida (en 2017 en el Campeonato Mundial de Lucha Libre cuando Karimi Machiani, un luchador iraní, se dejó vencer al final del juego para no enfrentarse a un oponente israelí en la próxima ronda). Respecto a la ruptura de relaciones entre países y protestas, encontramos incluso casos como el del futbolista alemán Mesut Özil, quien puso fin a su carrera como internacional tras las críticas expresadas después de la publicación de una fotografía que lo mostraba junto al presidente de Turquía, Recep Tayyip Erdogan, en el año 2018.

El deporte a nivel internacional va a menudo más allá del mero antagonismo bilateral, entendido incluso como el porqué de la revelación de elementos constructivos en la esfera de la diplomacia de la prevención (Villar, 2008), a través de la organización de conferencias, la mediación por parte de organizaciones internacionales, resoluciones a favor de un Estado, mediación, investigación de terceros o cumbres internacionales. Los grandes eventos deportivos se encuentran repletos de estas «acciones satélite», que finalmente terminan formando parte del propio evento. También es posible encontrar roles de diferentes comisiones pertenecientes a Federaciones Internacionales u organizaciones regulando y proponiendo acciones a favor del buen funcionamiento (del evento) o de la promoción de valores asociada al mismo.

Reconociendo el potencialmente negativo lado del multilateralismo, observamos que una situación de crisis favorece la aparición de reacciones (siempre desde la perspectiva de Villar, 2008) como el boicot, las resoluciones contra un Estado, o el apoyo a oponentes exiliados. Los ejemplos son numerosos y sería muy difícil decidir cuál es el más destacado, incluso aunque la transición al Olimpismo nos trajera a la mente los Juegos de Moscú (1980) y de Los Ángeles (1984).

\subsection{Diplomacia en el Olimpismo}

\subsubsection{La tregua Olímpica}

El ejemplo más simbólico es el de los Juegos Olímpicos. La tregua, uno de los pilares de la doctrina, debe ser respetada: por ello, algunos países estarían dispuestos a comprometer sus posiciones políticas para que no les fuera negada la oportunidad de competir. Tomando la herencia de la antigüedad, la Ekecheiria fue revivida por el presidente del COI, Juan Antonio Samaranch, en 1992.

\subsubsection{El marco olímpico}

Ya que las guerras a menudo emergen de diferentes puntos de vista políticos, el Comité Olímpico Internacional (COI) no promueve ideas políticas concretas, sino valores universales. Sin embargo, la relación entre el mundo del deporte y la política es compleja. Ambos mundos pueden cruzarse o superponerse mutuamente. Tal y como pudo verse en el caso de Sudáfrica, la política de Apartheid adoptada entre los años 1955 y 1992 supuso que el país se viera apartado de las competiciones deportivas internacionales en aquel período. Por el contrario, el deporte puede ser utilizado como pretexto, organizando eventos deportivos que guíen hacia el establecimiento de contactos diplomáticos. Por ejemplo, la República Popular de China y los Estados Unidos de América 
reanudaron su contacto gracias a un campeonato de tenis de mesa. Estos «intercambios internacionales», debido a su importancia y seguimiento mediático, dan lugar a la aparición de sentimientos de lealtad de identidad.

Es interesante examinar la primera gran encuesta del sociólogo francés Jean-Marie Brohm, dentro de su marco contextual y cronológico, ya que se centró en los Juegos Olímpicos de 1936. La ceremonia en honor al nazismo fue una de las primeras críticas llevadas a cabo hacia el régimen, pero en realidad no se hizo nada en su contra. Monique Berlioux, una figura prominente del COI, muestra cómo podría haberse evitado la Segunda Guerra Mundial si los Juegos Olímpicos de Alemania hubieran sido boicoteados. Si a la política le gusta afirmar su poder en los deportes, por el contrario, los deportes pueden ejercer el poder político gracias al control que sus instituciones pueden tener sobre ciertos estados (Richard, 2009).

\section{Consideraciones discursivas sobre la mediatización del deporte}

En esta segunda parte, pretendemos abordar los problemas sin la perspectiva epistemológica y metodológica. Comenzaremos con un breve enfoque en las representaciones del deporte por parte de los medios de comunicación, para posteriormente ofrecer detalles retóricos desde la perspectiva del análisis del discurso.

\subsection{Presentación del deporte por parte de los medios de comunicación}

\subsubsection{Consideraciones contextuales (socio-cultural, económicas y políticas)}

Uno de los conceptos más tratados en los estudios sociopolíticos internacionales es la globalización. Pascal Boniface, director del Instituto de Asuntos Internacionales y Estratégicos (IRIS), ha dedicado varios libros a la correlación existente entre el deporte (especialmente el fútbol) y esta temática. Sin necesariamente buscar las causas de dicha circunstancia, es innegable que el fútbol es un fenómeno global, como prueban los siguientes ejemplos, que datan ya de quince años atrás:

«15.000 copias de la revista del Manchester United han sido distribuidas en Tailandia. La Juventud de Turín cuenta con 1200 clubes de fans en todo el mundo. Real Madrid TV, el canal del club, se emite en 40 países'» (Boniface, 2006).

Un ejemplo más antiguo nos muestra el enorme poder de atracción que tiene el deporte. Como menciona Jean-Francois Bourg, la primera emisión de un partido en directo en Francia data del año 1950. El partido, de alto simbolismo en aquel momento, enfrentó al equipo francés y al equipo alemán. En aquellos años, apenas había 1500 televisores en todo Francia. En los días previos al partido, se vendieron 1000 aparatos de televisión cada día.

Es interesante ver qué distinciones se pueden hacer entre los mercados mundiales y los juegos (mundiales). Al mismo tiempo, se puede lograr la consecución de varios objetivos a través del fútbol, que se convierte en el medio utilizado para promover intereses y transmitir mensajes; incluso si los equipos juegan en un campeonato nacional, participan en campeonatos internacionales y a menudo tienen varias nacionalidades entre sus jugadores. Somos testigos de una globalización del deporte que va de la mano de la globalización de los mercados económicos y mediáticos. 


\subsubsection{Dimensiones semejantes a una guerra}

El lenguaje asociado a las prácticas deportivas a menudo se señala como similar al lenguaje utilizado en un contexto militar (Bonnet, 2010). Las metáforas a menudo nos llevan del campo de batalla militar a los campos de enfrentamientos deportivos.

Si bien sería demasiado largo enumerar todas las palabras y expresiones militares que han sido tomadas prestadas por los deportes, es necesario mantener esta consideración general para comprender más adelante su impacto simbólico. De hecho, con palabras de tal calibre, la transposición puede inclinarse para acentuar determinados aspectos, particularmente en el campo de la retórica que continúa a este texto.

\section{2- Aclaraciones retóricas}

Para observar y analizar desviaciones, existen varios trabajos importantes en los estudios de medios, destacando especialmente el Análisis Crítico del Discurso. Desde un punto de vista retórico, en un artículo sobre el racismo de las élites, Teun Van Dijk afirma, en relación con los discursos racistas, que:

«En general, la representación del Otro enfatiza la diferencia, la desviación y la amenaza. La negación rutinaria, o la subestimación del racismo, es parte de la estrategia general positiva de auto-presentación, especialmente entre las élites.»(Van Dijk, 2005, p.49)

En un contexto internacional, por lo tanto, es importante ver en detalle cómo esta diplomacia se refleja en los medios de comunicación. T. A. Van Dijk propone observar fenómenos al nivel «más local» de la semántica (cotidiana). Habla de renuncias o advertencias («avertisseurs» en francés), es decir, «movimientos semánticos» con una parte positiva sobre Nosotros y una parte negativa sobre Ellos. Los ejemplos listados incluyen:

- Negación aparente: no tenemos nada contra X, pero...

- Concesión aparente: algunos de ellos son inteligentes, pero en general...

- Empatía aparente: Por supuesto, X ha tenido problemas, pero...

- Ignorancia aparente: no lo sé, pero...

- Excusas aparentes: lo siento, pero...

- Reversión: no ellos, pero somos las verdaderas víctimas...

- Transferencia: no me importa, pero mis clientes...

Destacan dos elementos clave: la negación y el «pero». El poder de la negación es bien conocido. Cualquier oración negativa hace que se escuche su «versión» afirmativa. En este caso, es un distanciamiento del discurso racista. Sin embargo, la negativa expresada (en la oración) no se resuelve para negar completamente el punto. Esto es evidente en las tres primeras formas. Las siguientes se centran menos en logos y más en ethos y pathos. Se admite la ignorancia o la excusa para absolverse de cualquier reproche, pero lo que sigue no es más que una declaración racista. 
Dichas formulaciones todavía existen en los discursos de mediación deportiva. Desafortunadamente, mientras algunos aún se expresan con una discriminación fuerte y vulgar, siempre es posible observar la subsistencia de una devaluación del Otro que a menudo se refleja en una representación de la diplomacia del deporte. Para ver (las cosas) más claramente y llevar el análisis más allá, debemos teorizar esta dialéctica aplicándola al Olimpismo.

\section{Representación mediática del deporte y las nacionalidades}

En esta tercera y última parte, proponemos continuar la aplicación hacia un marco olímpico utilizando el concepto dialéctico de lo Mismo y lo Otro. Finalmente, terminaremos con la ilustración de los medios y las nacionalidades olímpicas, a menudo bastante alejadas de las administrativas u oficiales (Bruce, 2004). A fin de elevar la dimensión constructivista de la propia representación mediática, concluiremos tratando la fuerza de los efectos semánticos más allá de las bases fundamentales legales o formales.

\subsection{El Yo olímpico y el Otro olímpico}

La dialéctica del Ser y el Otro debe entenderse como un proceso dinámico. Como cualquier elemento que tenga sentido, el Ser y el Otro son productos de esta dinámica.

El Yo distingue elementos, personas o miembros que pueden identificarse como parte del mismo conjunto. Este conjunto es flexible y puede fluctuar de un discurso a otro, siendo los límites siempre variables. La dialéctica del Ser y del Otro, en la que se construyen las identidades sociales, los conflictos lingüísticos y las imágenes del lenguaje, es al mismo tiempo:

— interpersonal: Nosotros (comunidad) / Ellos (externo a la comunidad)

- espacial: el Yo anclado aquí, los Otros rechazados en otro lugar;

- lingüística: adopción de «nuestro propio código» (idioma o variedad lingüística local), o respeto de «su propio código» (idioma dominante y de mayor circulación);

- representacional: los «sistemas de valores», creencias, también se refieren a espacios particulares, con la misma dialéctica de integración / exclusión.

Si colocamos esta función dentro de una dimensión social, es más fácil entender cómo funciona el dominio en sí. Consiste en mantener al grupo dominado en su lugar para permitir que el grupo dominante mantenga su posición. «Las culturas, y especialmente las culturas nacionales, resuenan con las voces de los poderosos y están llenas de los silencios de los impotentes» (Kramsch, 1998, p. 9).

Sin embargo, el marco olímpico no tiene como objetivo crear o mantener una forma de dominio, por lo que de acuerdo con estos cuatro criterios podemos encontrar las características:

— interpersonal: Nosotros para los participantes (olímpicos);

- espacial: anclar el Aquí con la realización de los Juegos Olímpicos (y por extensión, del entrenamiento preparatorio y las ceremonias); 
- lingüística: respeto de «su propio código» que puede ser nuestro propio código con francés, inglés y el idioma o los idiomas del Comité organizador (idiomas dominantes y de amplia circulación junto con el idioma anfitrión como complemento);

- representacional: los «sistemas de valores», creencias, también se refieren a espacios particulares, con los valores olímpicos (excelencia, amistad, respeto) como vectores de integración (se puede encontrar una forma de exclusión en el incumplimiento de sus valores y de las reglas específicas de cada deporte).

La intersección de elementos sociopolíticos y discursivos denota la importancia de los pequeños detalles a la hora de reflejar la fuerza atribuible a los valores olímpicos. Por esta razón, en sus logros más visibles (es decir, en los medios de comunicación internacionales), es deber de quienes los defienden pensar también en la forma en que cada representación está expresando estos ideales de forma alta y clara.

\subsection{Medios de comunicación y nacionalidades olímpicas}

Las nacionalidades de los medios de comunicación deportivos a veces pueden ser diferentes de las que aparecen en los pasaportes de las personas. Así pues, la nacionalidad oficial y administrativa no siempre coincide con la nacionalidad que se muestra en la camiseta. Esto se puede observar en varios casos; uno de los más llamativos es el caso de la doble nacionalidad: con dos opciones posibles, solo se podrá utilizar una y esto a veces puede tener consecuencias, al ser la alternancia de mayor complejidad (además de altamente regulada en ciertos períodos). También encontramos participación simplemente a modo de membresía en el equipo nacional, que algunos llaman identidad deportiva nacional (sin tener el pasaporte del equipo nacional, el individuo viste la camiseta). En el atletismo, por ejemplo, hay varios casos de deportistas de países de África Oriental que, bloqueados por una fuerte competencia en su propio país (y en ocasiones potencialmente atraídos por mejores condiciones materiales), visten los colores de los países asiáticos en los campeonatos internacionales, siendo estas decisiones muy poco apreciadas en sus países de origen.

Fuera del marco de los Juegos Olímpicos, es posible encontrar en diferentes eventos internacionales la práctica del comentarismo de televisión utilizando la categorización de medios contractuales (CMC, ver Richard, 2009). Se hace referencia a los jugadores según la nacionalidad de su club, independientemente de su propia nacionalidad. Durante la transmisión de un partido de la Copa de la UEFA, dos jugadores del equipo Zenit Saint-Petersburg fueron llamados «dos rusos», aunque uno es surcoreano y el otro holandés. De esta forma, el marco deportivo colectivo favorece la categorización colectiva, incluso cuando esta puede inducir a error. Desde una perspectiva diplomática, el instrumento natural del lenguaje tiene prioridad sobre todos los demás.

\section{Conclusión}

El deporte, en su dimensión física de confrontación real o incluso simbólica entre individuos, establece una relación particular entre el ser humano y el cuerpo. Durante el transcurso de los eventos deportivos, la propia participación otorga la esperanza de poder formar parte algún día de los sucesos que previamente se veían en los medios de comunicación (Tervo, 2002). Particularmente durante los eventos internacionales y debido a que la modalidad de selección no siempre tiene como base la meritocracia, los atletas jugarán «más que solo un juego». Por esta razón, los discursos que los marcarán serán aquellos que caractericen a los individuos ajenos a ellos mismos. 
A menudo somos testigos de un fenómeno de transposición de las representaciones generales que nos hacemos de las sociedades de las que proceden los atletas y equipos nacionales de la que muestran ellos mismos. La nacionalidad es una opción, frecuente, neutralizada por muchos elementos como los logotipos en las camisetas, los himnos, las banderas, etc. Sin embargo, entran en juego otras dinámicas de identidad, en particular la dimensión étnica o racial.

«El deporte es cultural y políticamente importante desde el punto de vista de la representación de individuos y grupos. En relación con los individuos, el deporte propone un discurso sobre el cuerpo en sí mismo, su eficiencia o su estética; mientras que los equipos son una representación simbólica de sociedades locales o nacionales» (Ndiaye, 2008, p.224).

Brevemente, hemos tratado de analizar cómo el deporte puede tener objetivos claramente diplomáticos dentro del Movimiento Olímpico. Sin embargo, más allá de la función instrumental del deporte, hemos tratado de mostrar que también existe una reestructuración de la realidad con representaciones que pasan por discursos que muestran a los Estados o grupos simbólicos en formas que difieren del simple marco oficial. Con sus valores universales, el Olimpismo nos da las claves para tratar de vivir en el respeto, pero debemos asegurar la excelencia de nuestras palabras y acciones para mantener los lazos de amistad entre todos.

\section{Bibliografía}

— Berlioux, M. (2007). Des jeux et des crimes: 1936 le piège blanc olympique. París: Atlantica.

- Bonnet, V. (2010). Le stéréotype dans la presse sportive : vision de l'identité à travers l'altérité. Signes, Discours et Sociétés [en ligne], 4. Visions du monde et spécificité des discours. Recuperado de http://revue-signes.info/document.php?id=1417.

- Boniface, P. (2006). Football et mondialisation. París: Armand Colin.

- Bourg, J. F. (1988). Le sport en otage. París: La Table ronde.

— Bourg, J. F. (1994). L'argent fou du sport. París: La Table ronde.

- Bruce, T. (2004). Making the boundaries of the "normal" in televised sports: the play-by-play of race. Media, Culture and Society, 26(6), 861-879. London: SAGE. https://doi.org/10.1177/0163443704047030

- Détrie, C., Siblot, P. y Vérine, B. (Eds.) (2001). Termes et concepts pour l'analyse du discours. Honoré Champion. París: Honoré Champion.

- Kramsch, C. J. (1998). Language and culture. Oxford: Oxford University Press.

- Ndiaye, P. (2006). Questions de couleurs : histoire, idéologie et pratique du colorisme. En D. Fassin y É. Fassin (Eds.), De la question sociale à la question raciale. París: La Découverte.

- Ndiaye, P. (2008). La Condition noire. Essai sur une minorité française. Paris : Calmann-Lévy.

- Richard, A. (2009). Les discours sportifs en proie aux nationalismes et à l'ethnicisation. (Tésis doctoral bajo la dirección de Claire Kramsch-University of California Berkeley - y Paul Siblot-Université Paul-Valéry Montpellier 3-). Recuperada de http://tel.archivesouvertes.fr/tel-00440902 
— Tervo, M. (2002). Sports, "race" and the Finnish national identity in Helsingin Sanomat in the early twentieth century. Nations and Nationalism,8(3), Asen. https://doi.org/10.1111/1469$\underline{8219.00054}$

- Villar, C. (2008). Le discours diplomatique. París: L'Harmatt. 